\title{
Klinefelter syndrome: a speech-language and neuropsychological assessment
}

\author{
Dionísia Aparecida Cusin Lamônica ${ }^{(1)}$ \\ Camila da Costa Ribeiro(1) \\ Mayara dos Santos Baldin (2) \\ Maria de Lourdes Merighi Tabaquim ${ }^{(1,2)}$
}

(1) Faculdade de Odontologia de Bauru, Universidade de São Paulo, Bauru, São Paulo, Brasil.

(2) Hospital de Reabilitação em Anomalias Craniofaciais - Universidade de São Paulo, Bauru, São Paulo, Brasil.

Conflict of interests: Nonexistent

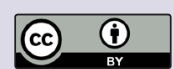

Received on: April 25, 2018

Approved on: September 21, 2018

Corresponding address:

Dionísia Aparecida Cusin Lamônica

Rua: Via Puccini, n0 1-16, Bairro Tivolli

CEP: 17053-095 - Bauru, São Paulo, Brasil E-mail: dionelam@uol.com.br

\section{ABSTRACT}

The Klinefelter syndrome is a chromosomal aneuploidy caused by additional $\mathrm{X}$ chromosomes in men. The diagnosis is made by clinical observation and karyotype examination. Besides other characteristics, the phenotype involves infertility, hypogonadism, gynecomastia, and cognitive alterations, mainly in the language domain. This paper describes the case of a teenager with Klinefelter syndrome and history of difficulties in the learning process, behavioral and communication problems. The ethical guidelines were followed in the present report. The cognitive-communicative, pragmatic and syntactic profile was drawn from the speech and neuropsychological evaluations. The speech-language assessment showed deficits in expression and comprehension. Difficulties were also found in phonological awareness, mathematical operations, reading and writing, access to the lexicon, alterations in pragmatics and occasionally, in syntactics. The neuropsychological evaluation indicated impairments in tasks that require the identification of similarities, establishment of cause-effect relationships and analogies, demonstrating a compromised reasoning for logical operations, with intellectual level incompatible with the chronological age. This interdisciplinary clinical study favors intervention approaches in rehabilitation, to maximize the potential of the individuals affected, contributing to improve their quality of life.

Keywords: Klinefelter Syndrome; Language; Cognition; Interdisciplinary Research 


\section{INTRODUCTION}

The Klinefelter syndrome (KS) is a chromosomal aneuploidy caused by additional $X$ chromosomes in men. The trisomy $(47, X X Y)$ corresponds to $80-90 \%$ of cases, being considered the most common sexual chromosomopathy, even though there are also tetrasomies $(48, X X X Y$ or $48, X X Y Y)$ and even pentasomies $(49, X X X X Y){ }^{1}$. Its prevalence is around one in every 1,000 livebirths $^{2}$.

The diagnosis is made by clinical examination and karyotype testing. Besides other characteristics, the phenotype includes infertility, hypogonadism, gynecomastia, cognitive disorders, especially in the language domain, besides psychiatric alterations ${ }^{2-7}$.

Patients with KS tend to present difficulties in the regulation of emotions and behavior, affecting the relationship with their peers ${ }^{2-7}$. Babinet et al. $(2017)^{8}$ suggested that disorders in social cognition are part of the phenotypic aspects of KS. They presented immaturity, insecurity, shyness, low self-esteem, learning difficulties, impaired judging capacity and non-assertive behavior, characterized by a radical antagonism of passivity and aggressivity ${ }^{9}$, as well as high rates of distress, neuroticism and introversion ${ }^{10}$, besides being more susceptible to psychiatric comorbidities as anxiety, depression and conduct disorders ${ }^{11}$, bipolar affective disorder, schizophrenia, autism and $\mathrm{ADDH}^{12,13}$. The cognitive disorders commonly observed include IQ below average, deficits in attention and frontal-executive functions, planning ability, mental flexibility and inhibitory control ${ }^{9,10}$, and difficulties in motor development, fine and gross motor skills, similar to symptoms of dyspraxia.

There is consensus in the literature about the intense difficulty in communication in individuals with $\mathrm{KS}^{2-6}$. Important deficits in expressive and receptive language were described, as well as alterations in short-term verbal memory, comprehension and utilization of grammar rules, speech-language processing and the literacy process ${ }^{4,14,15}$. Additionally, there are limitations in written expression and arithmetic, being classified into specific learning disorders as dyslexia and dysorthography.

The treatment of KS addressed the physical, cognitive and behavioral symptoms and social interaction $^{16,17}$. The physical treatment mainly includes the replacement of testosterone levels, since several phenotypic aspects are related with deficiency of this hormone ${ }^{2-7}$. The cognitive disorders tend to be milder if the diagnosis is made prenatally, which increases the chances of early hormone and psychological intervention ${ }^{6}$. The early diagnosis is still hardly accessible, increasing the challenges to the families, who must go through a long and difficult process to understand the cognitive and psychosocial difficulties experienced by the children, besides the difficult access to multidisciplinary treatment, which is necessary for rehabilitation ${ }^{18}$.

Despite the abundant literature about the cognitive profile of patients with KS, the interdisciplinary communication among different health specialties, such as Speech-Language Pathology and Neuropsychology, is important for full comprehension of the patient's disorders and better planning of therapeutic strategies to minimize the characteristic sequelae of this syndrome. Thus, this paper reports the case of an adolescent with KS and history of difficulties in the learning process, behavioral and communication problems. His cognitive profile was delineated based on speech-language and neuropsychological assessment, aiming to describe the findings that may favor intervention approaches in the rehabilitation processes for this affected population.

\section{CASE REPORT}

The ethical guidelines were met for the present case report. The case study was approved by the Institutional Review Board of Bauru School of Dentistry - University of São Paulo (protocol n. 1.113.969). The family signed an informed consent form, according to Resolution 466/12 of the National Commission of Ethics in Research.

The child was born at term weighing 2,670 grams with a length of 46 centimeters. He was adopted at the age of one year and nine months, in situation of undernourishment, lack of basic care and affectivity. He was submitted to heart surgery at two years of age due to malformation. During early childhood he was easily irritable, with short periods of sleep and episodes of apnea. He presented weak suction, reflux, undernourishment and low weight gain. Until four years of age he only ate soft foods. He started to walk at two years, spoke the first words at four years and presented difficulties in school. Currently at the age of 14 years, he presents marked limitations to express himself, using short sentences and presenting difficulties in narration, such as to report facts that occurred in school, tell about a movie he watched, a situation he experienced, and others. He is attending the $6^{\text {th }}$ school grade, according to the continued progression guideline. $\mathrm{He}$ was described by his parents as shy, impulsive and anxious, having few friends. He presents signs of 
irritability, skin-picking behavior, auditory command hallucinations, low tolerance, sudden mood changes and aggressivity, making use of psychiatric drugs for psychotic symptoms. The medical evaluation and karyotype assessment (47, XXY) confirmed the KS.

The investigation of speech-language and neuropsychological competences included interview with the caretakers and specific instruments of each area. Due to the evident limitations of the individual during the evaluation process, some instruments were used at lower age level than his chronological age, aiming to delineate the profile of developmental age of the adolescent.

Therefore, the following instruments were applied for speech-language assessment: Profile of SpeechLanguage Abilities (PSLA) ${ }^{19}$, School Performance Test $(\mathrm{SPT})^{20}$, Peabody Picture Vocabulary Test (PPVT) ${ }^{21}$, Tests for Evaluation of Reading Processes (TERP) ${ }^{22}$, Token Test (Token) $)^{23}$, Rapid Automatized Naming Test (RANT) ${ }^{24}$ and Syntactic Awareness Test (SAT) ${ }^{25}$. These instruments were selected considering that most difficulties were related to the school performance. Therefore, a profile of the adolescent was delineated concerning the reading and writing abilities.
The neuropsychological assessment employed normalized instruments to identify the abilities of intellectual function, with application of Raven's Progressive Matrices - General Scale ${ }^{26}$, Wechsler Intelligence Scale for Children - WISC- IV27; the perceptual-motor level was assessed by the Bender Perceptual-Motor Graphic Test, with correction based on Santucci28; the executive functions were analyzed by the Wisconsin Cards Sorting Test - WCST ${ }^{29}$; and the behavioral aspects and family dynamics were analyzed by the Parenting Style Inventory - IEP ${ }^{30}$

\section{RESULTS}

The results observed in speech-language assessment (Table 1) indicated deficiencies in expression and comprehension. Additionally, the tests also revealed alterations in the phonological awareness level, difficulties in simple mathematic operations (addition and subtraction), reading and writing of trisyllable words, difficulty in access to the lexicon (increased latency time), alteration in pragmatics, production of simple sentences, occasionally with syntactic alteration. Concerning the comprehension, complex and abstract commands were more hardly understood and often required repetition.

Table 1. Classification of speech-language assessment

\begin{tabular}{|c|c|c|c|}
\hline FUNCTION ANALYZED & TEST EMPLOYED & RESULT & CLASSIFICATION \\
\hline Speech-language abilities & $\begin{array}{l}\text { Profile of speech-language } \\
\text { abilities }\end{array}$ & $\begin{array}{c}40 \text { points } \\
\text { (compatible with six years) }\end{array}$ & Deficient \\
\hline Reading, writing and arithmetic & School performance test & $\begin{array}{l}\text { Inferior low for } 1 \text { st grade, in the } \\
\text { three abilities }\end{array}$ & Deficient \\
\hline Receptive vocabulary & $\begin{array}{c}\text { Peabody Picture Vocabulary } \\
\text { Test }\end{array}$ & Inferior low & Deficient \\
\hline Reading & $\begin{array}{l}\text { Tests for Evaluation of Reading } \\
\text { Processes }\end{array}$ & $\begin{array}{l}\text { Great difficulty in the reading } \\
\text { and interpretation process }\end{array}$ & Deficient \\
\hline Verbal comprehension & Token Test & $\begin{array}{c}27 \text { points } \\
\text { (10th percentile - eight years) }\end{array}$ & Deficient \\
\hline Access to the lexicon & Rapid Automatized Naming Test & $\begin{array}{l}\text { Result compatible with 2nd } \\
\text { grade children }\end{array}$ & Deficient \\
\hline Metasyntactic ability & Syntactic awareness test & $\begin{array}{c}38 \text { points } \\
\text { (average for 2nd grade) }\end{array}$ & Deficient \\
\hline
\end{tabular}


The results of neuropsychological assessment (Table 2) indicated damage to tasks that demanded the identification of similarities, establishment of causeeffect relationships and analogies, demonstrating impaired reasoning for logical operations, with intellectual level incompatible with the chronological age, characteristic of intellectual deficiency.

Table 2. Tests, cognitive function, percentiles and classifications of neuropsychological cognitive assessment

\begin{tabular}{|c|c|c|c|}
\hline COGNITIVE FUNCTION & TEST / SUBTEST / ABILITY & PERCENTILE & CLASSIFICATION \\
\hline \multirow{6}{*}{ Intellectual } & WISC - Intelligence quotient & 0.3 & Deficient \\
\hline & Verbal Comprehension Index & 11 & Deficient \\
\hline & Perceptual Organization Index & 0.1 & Deficient \\
\hline & Processing Speed Index & 30 & Medium \\
\hline & Operational Memory Index & 0.1 & Deficient \\
\hline & Raven's Progressive Matrices & 11 & Deficient \\
\hline \multirow{4}{*}{ Memory } & WISC - digits & 0.1 & Deficient \\
\hline & WISC - sequence of numbers and letters & 11 & Deficient \\
\hline & WISC - vocabulary & 11 & Deficient \\
\hline & WISC - information & 0.1 & Deficient \\
\hline \multirow{9}{*}{ Executive functions } & WCST - failure to maintain set & $2-5$ & Moderate \\
\hline & WCST - perseverative responses & 13 & Moderate \\
\hline & MWCST - number of completed categories & $11-16$ & Borderline \\
\hline & MWCST - learning to learn & $2-5$ & Moderate \\
\hline & WISC - similarities & 55 & Borderline \\
\hline & WISC - figurative concepts & 11 & Deficient \\
\hline & WISC - comprehension & 55 & Borderline \\
\hline & WISC - matrix reasoning & 11 & Deficient \\
\hline & WISC - word reasoning & 33 & Borderline \\
\hline \multirow{3}{*}{ Visual attention } & WISC - codes & 63 & Average \\
\hline & WISC - cancelling & 116 & Inferior medium \\
\hline & WISC - symbol search & 99 & Inferior medium \\
\hline \multirow{7}{*}{$\begin{array}{l}\text { Visual-constructive } \\
\text { perception }\end{array}$} & WISC - completing figures & 55 & Borderline \\
\hline & WISC - cubes & 0.1 & Deficient \\
\hline & Global Gestalt Bender Santucci Test & 8 years & Deficient \\
\hline & Angles & 9 years & Deficient \\
\hline & Spatial orientation & 6-7 years & Deficient \\
\hline & Relative position & $10-14$ years & Inferior medium \\
\hline & Koppitz & $20.8 \%$ indicators & Inferior \\
\hline Academic ability & WISC - Arithmetic & 0.1 & Deficient \\
\hline
\end{tabular}

Legend: WISC: Wechsler Intelligence Scale for Children; WCST: Wisconsin Cards Sorting Test

The evaluation of family dynamics indicated marked discrepancy between parents' perception about their child education, and those perceived by him about the parenting practices. While the son indicated behaviors that indicated risky parenting practices, with less easiness to demonstrate affection and emotions, predisposing to hostile or indifferent behaviors in the family dynamics, the parents indicated more positive behaviors.

\section{DISCUSSION}

This paper aimed to describe a case of KS, with speech-language and neuropsychological assessment. During the interview/anamnesis process, the caretakers reported some characteristics noticed in early childhood, such as delayed language development and learning difficulties. The literature describes that early childhood can be marked by delayed language, behavioral and cognitive development ${ }^{15}$. 
The speech-language assessment (Table 1) revealed several changes in oral and written language levels, corroborating the phenotypic findings of the syndrome $e^{2-6}$. In language performance, no symmetry was observed in the development of receptive and expressive abilities, with greater deficiencies in expressive ability. These findings were also reported by several other studies ${ }^{3,4,6}$. An alteration was noticed in the elaboration of sentences, usually simple, with few elements and syntactic changes concerning the use of verbal tenses, besides pragmatic difficulties. The literature describes that the late development of language and speech may persist beyond childhood, with problems in syntactic production and narrative competence $^{13,15}$. Significant problems were also observed in learning abilities, with deficiencies in all tests applied. The literature is consensual about the problems resulting from the syndrome, indicating disorders in learning ${ }^{3,4,6,7}$, reading skills ${ }^{3,7}$ and arithmetic calculations ${ }^{5}$.

Shanlee et al. ${ }^{3}$ emphasized that the high prevalence of learning difficulties in KS justifies the regular neuropsychological assessment for all children with this disorder, starting at onset of elementary school, at the early stage of literacy and when difficulties are still incipient.

Concerning the intelligence quotient, the global cognitive performances were deficient, indicating impairment in fundamental skills for learning, such as the ability to form concepts, verbal and non-verbal reasoning, perceptual organization, visual-motor integration and operational memory. Gravholt et al. ${ }^{6}$ reported that individual with $\mathrm{KS}$ have lower IQ, with greater deficiencies in verbal abilities rather than executive abilities, yet not enough to constitute intellectual deficiency, which was corroborated in the present case. High risk factors (intrinsic conditions) and low protective factors (such as late diagnosis) may have contributed to the severity of the disorder. Since the diagnosis was not achieved early, it may be considered that the risk factors involved may have had greater influence on the efficiency of intellectual and cognitive functions, such as language.

The individual presented low performance in visualperception and visual-construction tasks, as well as in tasks that required praxical skills. Zampini et al. ${ }^{4}$ described the existence of deficiencies in fine and gross motor skills. The immaturity observed in the graphicperceptual-motor system justified the impaired domain of praxical skills for writing and numerical operations.
Executive functions are known to be impaired in KS with damage to mental flexibility in cognitive tasks ${ }^{9,12}$. The ability of abstraction of verbal concepts presented deficient scores, achieving borderline classification for the visual-spatial stimulus. The individual presented moderate difficulty in benefiting from environmental hints to reduce the number of errors and solve problems that required moral and ethical judgment, evidencing immaturity in the resolution of personalsocial issues. The ability of flexible thinking, in accordance with environmental contingencies, was below average, as well as the inhibitory control, a condition evidenced by the difficulty to sustain the reasoning and attention to maintain the context. The verbal and short-term semantic memory and the auditory-verbal operational memory had deficient scores. In selective attention subtests, there was a tendency to distraction in the presence of irrelevant stimuli, with scores below average. Skakkebæk et al. ${ }^{10}$ associated the memory skills and executive functions to limited logical reasoning, indicating lower intelligence. The same authors associated executive functions to restricted abilities of social cognition, which was corroborated in the present case study, indicating that the socialemotional difficulties involved in behavior regulation are phenotypic cognitive characteristics of this syndrome ${ }^{11,17}$.

The assessment of parenting practices indicated a risk factor for the generation of conflicts and unstable relationship between parents and $\operatorname{son}^{30}$. The family problems resulting from this situation were also described in the literature ${ }^{11}$, increasingly highlighting the importance of psychoeducational proposals to increase the assertive behavioral repertoires in the family ${ }^{18}$. The impairments observed in neuropsychological association functions, implied in memory, language, thought organization, inhibitory control, and others, suggested involvement of the higher association cortex. Skakkebæk et al. ${ }^{10}$ did not observe correlation of altered brain volumes in this population when correlated to cognitive test scores; however, the findings suggest that difficulties in cognitive and adaptive development may be related to atypical conditions of the brain micro-architecture.

The speech-language and neuropsychological assessments were correlated and complementary, evidencing the importance of both evaluations in the process of diagnosis and follow-up of children with the disorders observed in KS. The findings of the neuropsychological assessment are related to the findings of 
the speech-language assessment, while the impaired reasoning of logical operations, identification of similarities, establishment of cause-effect relationships and the ability of abstraction of concepts interfere with the development of expressive, comprehensive, pragmatic, and syntactic language, reading, writing, speechlanguage awareness and part of numerical cognition, such as the ability to perform mathematical calculations, which were also impaired in the speech-language assessment.

\section{CONCLUSIONS}

This clinical study aimed to present the clinical phenotype of KS with its effects on cognitive, linguistic, communicative and social processes. The interdisciplinary clinical study may be considered a differential of the present report, since it favors the interventive approaches for the rehabilitation process to broaden the potential of the individuals affected, besides contributing to improve their quality of life. The study limitations include the lack of longitudinal follow-up since early age, allowing identification of the influence of environmental aspects on the individual beyond the biological aspects, since the undernourishment, lack of basic care and affectivity experienced by the individual are known risk factors for the neurodevelopment.

\section{REFERENCES}

1. Bonomi M, Rochira V, Pasquali D, Balercia G, Jannini EA, Ferlin A. Klinefelter syndrome (KS): genetics, clinical phenotype and hypogonadism. J. endocrinol. invest. 2017;40(2):123-34.

2. Herlihy AS, Halliday JL, Cock ML, McLachlan RI. The prevalence and diagnosis rates of Klinefelter syndrome: an Australian comparison. Med. J. Aust. 2011;194(1):24-8.

3. Shanlee D, Howell S, Wilson R, Tanda T, Ross J, Zeitler $\mathrm{P}$ et al. Advances in the interdisciplinary care of children with Klinefelter syndrome. Adv Pediatr. 2016;63(1):15-46.

4. Zampini L, Burla T, Silibello G, Dall'Ara F, Rigamonti C, Lalatta F et al. Early communicative skills of children with Klinefelter syndrome. Clin Linguist Phon. 2018;32(7):577-86. DOI: 10.1080/02699206.2017.1384853.

5. Kanakis GA, Nieschlag E. Klinefelter syndrome more than hypogonadism. Metabolism. 2018;86:135-44. DOI: 10.1016/j.metabol.2017.09.017. (Epub ahead of print).
6. Gravholt $\mathrm{CH}$, Chang $\mathrm{S}$, Wallentin $\mathrm{M}$, Fedder J, Moore P, Skakkebaek A. Klinefelter syndrome - integrating genetics, neuropsychology and endocrinology. Endocr. Rev. 2018;39(4):389-423. DOI: 10.1210/er.2017-00212.

7. Van Rijn SV, Sonneville L, Swaab H. The nature of social cognitive deficits in children and adults with Klinefelter syndrome $(47, \mathrm{XXY})$. Genes Brain Behav. 2018;17(6). doi.org/10.1111/gbb.12465. (Epub ahead of print).

8. Babinet MN, Rigard C, Peyroux É, Dragomir AR, Plotton I, Lejeune $\mathrm{H}$ et al. Social cognition disorders in Klinefelter syndrome: A specific phenotype? (KS). Encephale. 2017;43(5):423-48.

9. Messina MF, Domenica LS, Aversa T, Pecoraro M, Valensize M, De Luca F. A characteristic cognitive and behavioral pattern as a clueto suspect Klinefelter syndrome in prepubertal age. J Am Board Fam. 2012;25(5):745-9.

10. Skakkebæk A, Bojesen A, Kristensen MK, Cohen A, Hougaard DM, Hertz J M et al. Neuropsychology and brain morphology in Klinefelter syndrome the impact of genetics. Andrology. 2014;2(4):632-40.

11. Ross JL, Kushner H, Kowal K, Bardsley M, Davis S, Reiss AL et al. Androgen treatment effects on motor function, cognition, and behavior in boys with Klinefelter syndrome. J Pediatr. 2017;185(10):193-9. e4.

12. Van Rijn S, Swaab H, Baas D, de Haan E, Kahn RS, Aleman A. Neural systems for social cognition in Klinefelter syndrome $(47, X X Y)$ : evidence from fMRI. Soc Cogn Affect Neurosci.2012;7(6):689-97.

13. Cederlöf M, Ohlsson GA, Larsson $H$, Serlahius E, Boman $\mathrm{M}$, Långtröm $\mathrm{N}$ et al. Klinefelter syndrome and risk of psychosis, autism and ADHD. J Psychiatr Res. 2014;48(1):128-30.

14. Bishop DV, Scerif G. Klinefelter syndrome as a window on the aetiology of language and communication impairments in children: the neuroligin-neurexinhypothesis. Acta Paediatr. 2011;100(6):903-7.

15. Zampini L, Draghi L, Silibello G, Dall'Ara F, Rigamonti C, Suttora C. Vocal and gestural productions of 24-month-old children with sex chromosome trisomies. Int $\mathrm{J}$ Lang Commun Disord. 2018;53(1):171-81.

16. Girardin CM, Lemyre E, Alos N, Deal C, Huot C, Van Vliet G. Comparison of adolescents with Klinefelter syndrome according to the circumstances of 
diagnosis: amniocentesis versus clinical signs. Horm Res. 2009;72(2):98-105.

17. Tartaglia N, Cordeiro L, Howell S, Wilson R, Janusz J. The Spectrum of the behavioral phenotype in boys and adolescents 47,XXY (Klinefelter Syndrome). Pediatric Endocrinology Reviews: PER. 2010;8(1):151-9.

18. Close S, Sadler L, Grey MJ. In the dark: challenges of caring for sons with Klinefelter syndrome. Pediatr Nurs. 2016;31(1):11-20.

19. Alvarez AMMA, Carvalho IAM, Caetano AL. Perfil de habilidades fonológicas. $2^{2}$ edição. São Paulo: Via Lettera. 2004.

20. Stein LM. Teste de Desempenho Escolar: manual para aplicação e interpretação (TDE). São Paulo: Casa do Psicólogo; 1994.

21. Dunn LM, Padilla ER, Lugo DE, Dunn LM. Teste de Vocabulário em Imagens Peabody (Peabody Picture Vocabulary Test), adaptação Hispanoamericana. American Guidance Service, Espanha: Circle Pines; 1986.

22. Capellini AS, Oliveira AM, Cuetos F. PROLEC: Provas de avaliação dos processos de leitura. São Paulo (SP): Casa do Psicólogo; 2010.

23. Malloy-Diniz LF, Bentes RC, Figueiredo PM, Brandão-Bretas D, Costa-Abrantes S, Parizze AM et al. Normalización de um abateria de tests para evaluar habilidades de comprensión linguaje, fluidez verbal y denominación em niños brasileños de 7 a 10 años: resultados preliminares. Rev. Neurol. 2007;44(5):275-80.

24. Denckla MB, Rudel RG. Rapid automatized naming of pictured objects, colors, letters and numbers by normal children. Cortex. 1974;10:186-202.

25. Capovilla FC, Capovilla AGS. Prova de Consciência Sintática (PCS normatizada e validada: para avaliar a habilidade metassintática de escolares de $1^{\text {a }}$ a 4a séries do Ensino Fundamental. São Paulo: Memnon; 2006.

26. Angelini AL, Alves ICB, Custódio EM, Duarte WF, Duarte JLM. Manual: Matrizes Progressivas Coloridas de Raven. São Paulo: Centro Editor de Testes e Pesquisas em Psicologia; 1999.

27. Wechsler D. Escala Weschsler de inteligência para crianças: WISC-IV. Manual Técnico. Tradução do manual original Maria de Lourdes Duprat. (4. edição). São Paulo: Casa do Psicólogo; 2013.

28. Cunha JA. Bender na criança e no adolescente. In: Cunha JA (org). Psicodiagnóstico-V (5.ed. revisada e ampliada). Porto Alegre, RS: Artes Médicas; 2000. p. 295-316.

29. Heaton RK, Chelune GJ, Talley JL, Kay GG, Curtiss G. Teste Wisconsin de Classificação de Cartas. São Paulo: Casa do Psicólogo; 2004.

30. Gomide PIC. Inventário de estilos parentais: Modelo teórico, manual de aplicação, apuração e interpretação. Petrópolis: Vozes; 2006. 